\title{
If larvae were smart: a simple model for optimal settlement behavior of competent larvae
}

\author{
Robert J. Toonen ${ }^{1, *, * *}$, Andrew J. Tyre ${ }^{2, * *}$ \\ ${ }^{1}$ School of Ocean and Earth Science and Technology, The Hawai'i Institute of Marine Biology, University of Hawaii \\ at Manoa, Coconut Island, PO Box 1346 Kane'ohe, Hawai'i 96744, USA \\ ${ }^{2}$ School of Natural Resources, University of Nebraska-Lincoln, 416 Hardin, East Campus, Lincoln, Nebraska 68583-0819, USA
}

\begin{abstract}
Much research has been done on larval settlement cues. Rather than having simple fixed responses to constant environmental stimuli, it seems likely that settlement decisions made by individual larvae should vary depending on the individual and the conditions under which it encounters that cue. Here, we present a simple stochastic dynamic programming model that explores the conditions under which larvae may maximize their lifetime fitness by accepting lower quality habitat rather than continuing to search for superior habitat. Our model predicts that there is a relatively narrow range of parameter values over which larval selectivity among habitat types changes dramatically from 1 (larvae accept only optimal substrata) to 0 (indiscriminant settlement). This narrow range coincides with our best estimate of parameter values gleaned from empirical studies, and the model output matches data for the polychaete worm Hydroides dianthus remarkably well. The relative availability of habitats and the total time available to search for high quality habitat (i.e. the ability to delay metamorphosis) had the greatest effects on larval selectivity. In contrast, intuitive factors, including larval energetics and mortality, showed little effect on larval habitat preference, but could still alter the proportion of larvae settling in different habitats by reducing search time. Our model predicts that a given larva may behave differently depending on where it falls in the optimality decision matrix at the instant in which it locates substrata. This model provides a conceptual framework in which to conduct future studies involving variability in settlement decisions among individual larvae, and in which to consider the selective forces driving the evolution of specific larval settlement cues. Our results suggest that a combination of the maximum search period and the relative frequency and quality of optimal habitat likely exert the greatest influence on the evolution of larval selectivity in the field.
\end{abstract}

KEY WORDS: Habitat choice $\cdot$ Larval settlement behavior $\cdot$ Desperate larva hypothesis $\cdot$ Stochastic dynamic programming model

\section{INTRODUCTION}

Differential larval settlement has been shown to have a major influence on the local abundance of adults (e.g. Strathmann et al. 1981, Keough 1983, Raimondi 1988), and substratum-derived chemical cues have been implicated in numerous studies as the mechanism by which larvae discriminate among habitats (reviewed by Meadows \& Campbell 1972, Crisp 1974, Chia \& Rice 1978, Pawlik 1992, Pechenik 1999).
Many larvae appear able to discriminate among habitats on the basis of physical factors such as light (e.g. Thorson 1964), hydrostatic pressure (e.g. Sulkin 1984), surface chemistry (e.g. Crisp 1965), and physical properties associated with the substrata (e.g. Wethey 1986, Raimondi 1988). The number of recent studies devoted to demonstrating the existence of chemical cues for larval settlement are legion, but few have succeeded in elucidating the structure of these compounds (reviewed by Pawlik 1992, Steinberg et al. 2002, Fusetani 
2004). Larvae typically delay metamorphosis in the absence of appropriate cues, although the ability to delay metamorphosis varies both with rearing conditions and among species (reviewed by Pechenik 1990). The specific cues which elicit larval settlement in the field remains a subject of considerable debate, and undisputed settlement inducers are still known for only a handful of species (reviewed by Pawlik 1992, Steinberg et al. 2002, Fusetani 2004).

Considering the quantity of evidence suggesting that larvae are able to discriminate accurately among both suitable and unsuitable substrata (reviewed by Woodin 1991), it is surprising that variation among individual larvae in settlement behavior has been largely marginalized (reviewed by Raimondi \& Keough 1990, Toonen \& Pawlik 2001a, Bishop et al. 2006). The usual adaptive explanation for larval response to settlement cues is increased average fitness (Raimondi 1988), and thus fixed larval responses to discrete settlement cues are expected; planktonic larvae spend some variable amount of time in the water column before settling into the benthos, and it is not obvious why there should be any individual variability among sibling larvae in their ability to evaluate and select an appropriate site for metamorphosis into the adult body form. However, larval behavior is not uniform in response to cues for settlement in virtually any study, and variability in larval response to discrete cues is the rule rather than the exception (Raimondi \& Keough 1990, Toonen \& Pawlik 2001a). This capacity for larvae to choose substrata based on their specific properties provides an obvious mechanism for variable dispersal among sedentary marine invertebrates (Krug 2001, Toonen \& Pawlik 2001a, Marshall \& Keough 2004). A growing body of life-history theory predicts that selection should favor genotypes that can vary their tendency to disperse in habitats that are spatially or temporally variable, or those that remain near their carring capacity (reviewed by Harrison 1980, Dingle 1996). Although many marine habitats appear to fit these criteria, confirmed examples of poecilogony (true developmental dispersal polymorphism) among the larvae of marine invertebrates are surprisingly rare (reviewed by Chia et al. 1996, Schulze et al. 2000, Gibson \& Gibson 2004). Recently, some authors have argued that the dispersal variability predicted by such theoretical work to occur in marine habitats may also be realized through individual behavioral differences among larvae resulting in differential transport or settlement preference rather than morphological dispersal polymorphisms common among such well-known organisms as terrestrial insects (e.g. Toonen \& Pawlik 1994, Krug 2001, Toonen \& Pawlik 2001a, Marshall \& Keough 2003).
Studies which specifically examine variability in settlement behavior among sibling larvae remain relatively rare in the literature (e.g. Toonen \& Pawlik 1994, Krug 2001, Marshall \& Keough 2003). If larvae are capable of determining whether a substratum is suitable for settlement, and larval settlement influences the patterns of adult distribution, then individual larval behavior ought to be an important aspect of larval supply. Furthermore, it is reasonable to expect that, as with many behaviors, individuals may differ in their responses to a given stimulus depending on their current condition and previous experience. For settlement, larvae ought to select substrata which impart the greatest expected lifetime reproductive success. However, this optimal habitat may change depending on the condition of the larva and the specific conditions under which it finds itself when locating substratum. Thus, the decision to continue searching for optimal substratum must be carefully balanced against the probability of surviving a search for that substratum and the availability of that substratum in the environment. If the substratum which imparts the greatest lifetime reproductive success is rare and the probability of dying while searching is high, accepting even a relatively poor site may be a better alternative than continued searching. This settlement dilemma should be of particular importance to larvae of sessile species, because once metamorphosed, there is no opportunity to recover from a poor choice of location. Where such dilemmas occur, an organism must choose among alternative behaviors in an effort to maximize its lifetime reproductive success, given the conditions under which it currently finds itself.

Given the nature of the settlement dilemma, a stochastic dynamic programming (SDP) model is particularly attractive (Mangel \& Clark 1988, Clark \& Mangel 2000). This approach begins with the premise that natural selection has acted on the behavior of individuals in such a way as to maximize their lifetime reproductive success within the constraints imposed by the organism's physiology and the environment in which it lives. Given this premise, it is possible to make predictions about the behavior that should be observed under varying external conditions and internal states (Mangel \& Clark 1988, Clark \& Mangel 2000). Mangel \& Clark (1988) argue that SDP models provide a unified approach to understanding animal behavior from an evolutionary standpoint, because an arbitrary number of behavioural types can be considered both simultaneously and sequentially, and physiological and environmental constraints are easily incorporated into the framework of the model. SDP models use risks and reproductive potentials corresponding to alternative behavioral strategies (the behavior set) to determine the optimal decision available to organisms under dif- 
ferent conditions at different stages of the life cycle (the state space).

We believe that an SDP approach is an excellent choice for this exercise, because such simulations do not require as many simplifications as are typically necessary to solve models analytically; therefore, a large number of additional factors could be incorporated into our model by expanding the code (an executable PC program and default input file-larval-model.exe and default.ini-and the $\mathrm{C}$ source code for the program are available as an online supplement at http://www.int-res.com/articles/suppl/ m349p043_apps/). Despite the potential strengths of a stochastic dynamic modeling approach, it has not been used previously in examining the settlement behavior of marine invertebrate larvae. Although much effort has already been spent modeling the evolution of mixed life-history strategies (e.g. Vance 1973a,b, Strathmann 1977, 1985, Christiansen \& Fenchel 1979, Caswell 1981, Jackson \& Strathmann 1981, Grant 1983, 1989), models examining the optimal substratum choice of individual larvae have not been published until recently. Thus, in the remainder of this paper we develop an SDP model for the decision whether to accept or reject a given substratum when encountered by a competent larva.

\section{THE MODEL}

In an SDP model there are 3 important components: (1) the state space, (2) the state dynamics, (3) the strategy set. In our model the state space is represented by a single variable $x_{(t)}$ (Table 1 ), the energy store $(x)$ of a larva at time $t$. Energy is gained by feeding, and lost through various metabolic costs; these processes represent the dynamics of that state variable through time. The strategy set is hierarchical (Fig. 1). First, larvae must decide whether or not to search for a substratum before they can make a settlement decision. If they do not search, they remain in the water column, gain energy from feeding, lose energy to metabolism, and experience some risk of mortality. If they choose to search, they can still gain energy from feeding, but less than if they had only fed (we discuss our reasons for these assumptions in greater detail below). They also experience an additional mortality risk of predation from benthic predators in addition to the risk associated with being in the water column while searching.

After a larva decides to search for a substratum, there is some probability that it will encounter a substratum during that search, and if successful, another decision is required whether or not to accept the encountered substratum. Here we present a simple model in which larvae are faced with an 'optimal' habi-

Table 1. List of model variable parameters, their description, and their default values for the simulations

\begin{tabular}{|lll|}
\hline Variable & \multicolumn{1}{|c|}{ Description } & Default value \\
\hline$\lambda_{i}$ & $\begin{array}{l}\text { Probability of finding habitat type } i \\
\text { (A = optimal; B = suboptimal) }\end{array}$ & $\mathrm{A}=0.1$ \\
$\alpha$ & Metabolic cost in water column & $\mathrm{B}=0.5$ \\
$\rho_{i}$ & Probability of survival to beginning of $t+1$ & Water column $=0.98$ \\
& (1 = water column; 2 = searching) & Searching $=0.98$ \\
$\sigma_{i}$ & Probability of survival to reproduction & Habitat A $=0.99$ \\
& by habitat (A = optimal; B = sub- & Habitat B $=0.95$ \\
$\delta$ & optimal habitat) & 1.2 \\
$\varphi$ & Metabolic gain from feeding & 1.0 \\
$\gamma$ & Energetic cost for metamorphosis & 1.0 \\
$T$ & Metabolic cost while searching & 60 \\
$x$ & Maximum number of time steps (PLD) & N/A \\
$C$ & Current energy state & 20 \\
$\bar{\chi}_{0}$ & Maximum possible energy state & 10 \\
$\sigma_{X}$ & Average initial energy state & 1 \\
& Standard deviation of initial energy state & \\
\hline
\end{tabular}

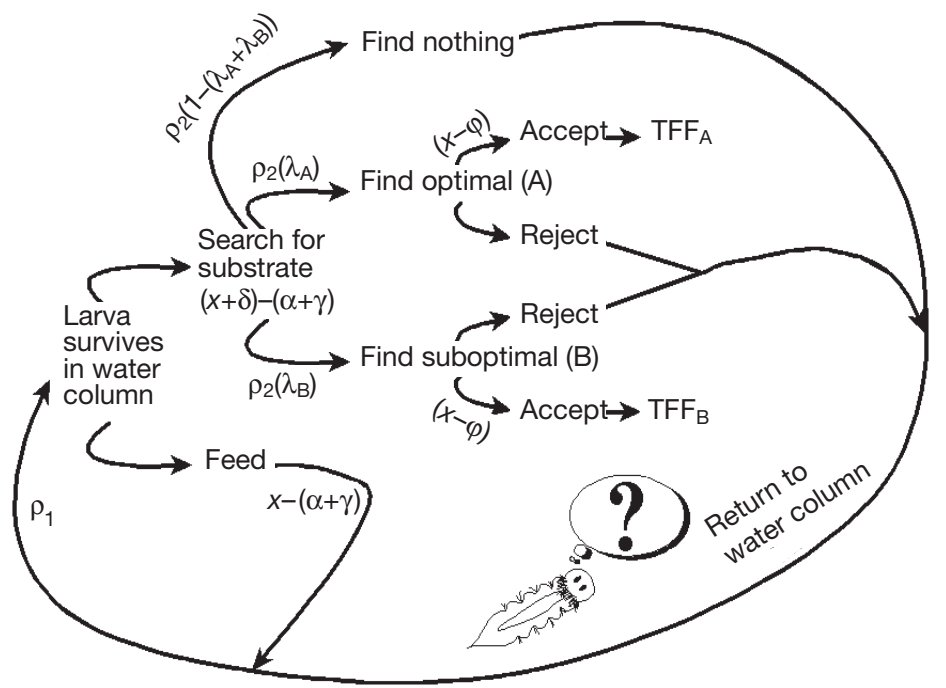

Fig. 1. A cartoon representation of the decision tree faced by a larva in our model. As explained in the text, 10000 larvae per spawn are generated by the model and each is run sequentially through this decision tree until at least $90 \%$ of them accept a substratum for settlement. Default parameter values for the model are presented in Table 1. TFF: Terminal fitness 
tat in which their fitness is maximal and a 'suboptimal' habitat in which their survival or fitness is reduced. Although we include only 2 habitat choices for simplicity, the suboptimal category could either be a single alternative or an average across many alternatives, and more types can easily be included in future versions of the model. In the absence of density dependence, when a larva encounters optimal habitat during a search, it should always choose to settle if it is competent. We do not force this decision in the model, however; larvae could potentially search, but reject both optimal and sub-optimal habitat if the expected payoff from settling does not exceed the expected payoff from delaying settlement. Likewise, suboptimal substrata may or may not be accepted, depending on the current energy reserves of an individual larva and the risks and payoffs associated with continuing to search for an alternate substratum. Once a larva accepts a given substratum on which to metamorphose, then its expected lifetime reproductive success is calculated based on the current energy state and the ultimate payoff (determined by the terminal fitness function) of the substratum on which it settled.

In the model there are a maximum number of time steps ( $T$, Table 1), beyond which the expected future reproductive success is 0 . We have set $T$ to 60 time steps arbitrarily, because a $60 \times 20$ matrix fits onto any standard computer monitor. During each time step, only a single behavioral decision can be made, so larvae can choose to feed or search for habitat but not both simultaneously. However, the results are qualitatively invariant even with order of magnitude changes in the value of the time horizon. The absolute value of $T$ is unimportant because the fitness function $F(x, t, T)$ is asymptotically independent of time and depends only on the state variable $x_{(t)}$ (Mangel 1989). The strategy associated with this asymptotic fitness function is called the stationary strategy. Setting the future reproductive success of individuals who are at the time horizon $(T)$ to 0 implies that there is some predictable maximum period of larval competency, beyond which larvae can no longer metamorphose and mortality is certain. While this is likely true for non-feeding (lecithotrophic) larvae, it is apparent that some feeding (planktotrophic) larvae may not experience a concrete time horizon in the same sense because many are capable of delaying metamorphosis significantly (reviewed by Pechenik 1990, 1999). For larvae that can continue feeding and delay settlement for variably prolonged periods, the stationary strategy is the more appropriate set of decisions to examine. The output of our model is generally stationary at time $<50$, and so examining the stationary strategy at time $=0$ will give us an idea of the optimal decision for those feeding larvae that lack the ability to accurately predict the end of their planktonic lifespan.

We have used the mortality estimate of Vance (Vance 1973b):

$$
\rho=\mathrm{e}^{m}
$$

where $\rho$ is the probability of dying per time unit (Table 1), and $m$ is a constant rate of mortality. This function assumes that mortality of larvae is neither state nor time dependent. The assumption of a constant rate of larval mortality is certainly unrealistic, because empirical studies suggest that larvae tend to become less prone to predation as they age (e.g. Rumrill et al. 1985, Pennington et al. 1986, Rumrill 1990). However, initial trials with our model, and results from previous studies (e.g. Ward 1987, Stamps et al. 2005) indicate that changing the mortality function has little effect on the qualitative results of the model. Mortality functions that varied randomly around a mean value, or that decreased throughout the planktonic period showed no qualitative effect on the model output. Using a mortality function that increases as larvae age does change the results of the model, but we are not aware of any empirical results to suggest older larvae are significantly more vulnerable to mortality than younger larvae. Therefore, we have chosen Vance's mortality function (Vance 1973a,b) for simplicity, with the understanding that settlement decisions are relatively unaffected by either a constant, random or decelerating rate of mortality. Regardless of the mortality function, we tried to use realistic estimates of natural instantaneous mortality rates (ranging from -0.0331 to $-0.8018 \mathrm{~d}^{-1}$ ) from the review of Rumrill (1990). Finally, we also assume that there is an added cost to searching for suitable habitat that is a result of reduced planktonic food, increased energy expenditure from penetrating and searching the boundary layer, and/ or direct exposure to benthic predators not encountered in the water column.

In this model, we assume that larvae possess no long-distance habitat detection mechanisms. In other words, habitats are encountered in direct proportion to their frequency of occurrence in the environment $\left(\lambda_{i}\right.$, Table 1). Although there are several studies in which larvae respond to appropriate substrata without direct contact (e.g. Chia \& Koss 1988, Lambert \& Todd 1994, Zimmer-Faust \& Tamburri 1994, Tamburri et al. 1996, Toonen \& Pawlik 1996), many of these responses are over such short distances as to be effectively contactdependent for the purposes of our model. In those cases where long-distance detection of suitable substrata appears possible in the field (e.g. Stoner 1994, Tamburri et al. 1996), the probability of encountering desirable habitat can simply be inflated relative to its absolute availability which would simulate this enhanced detection ability. 
Upon encountering substratum, larvae make a decision based on the expected payoff in the current habitat discounted by the risk associated with continuing to search for a better substratum; this decision implies that larvae are somehow able to assess that risk. Such risk assessment could be made through some integrative function of previous experience, or an innate estimate of the frequency of each habitat type in the environment. Although this may sound like a ridiculous assumption, there is some evidence that larval responses to substrata are modified by previous experience (e.g. Phillips 2002, Marshall \& Keough 2004, Botello \& Krug 2006, Gribben et al. 2006), and our assumption here is equivalent to assuming that the frequency of each habitat type does not change greatly over evolutionary time scales and that natural selection has favored those individuals that behave in the manner best suited to the environment in which they live. Thus, for the purposes of our model, we assume that natural selection has favored survival of larvae which settle in a manner most consistent with the long-term average of actual habitat frequencies. If the frequency of suitable habitats does change dramatically and unpredictably over short periods of time (such as among seasons), then a model that allows larvae to estimate the current frequency from previous encounters with each habitat type may be more appropriate; update learning could easily be incorporated into future models if this were considered more biologically realistic. We do not believe that such behavior is considered realistic by most larval biologists, and have not considered this possibility here.

The state variable $x_{(t)}$ can have values between 0 (below which larvae die of starvation), and some maximum value $\mathrm{C}$ (Table 1). We have no justification for this maximum energetic value, nor do we put any particular units on these quantities. For the sake of simplicity and generality, the energetic gain from feeding $(\delta)$, and the metabolic cost of maintenance in the water column $(\alpha)$ are considered purely as relative values that can be scaled to accommodate specific cases as necessary. We justify this simplified approach because we have found that it is the relative, rather than absolute values of energy gain to energy loss that are most important to the decision matrix, and these results are consistent with previous modeling efforts (reviewed by Stamps \& Krishnan 2005, Stamps 2006). A growing number of studies have determined species-specific larval energetic budgets in the laboratory (e.g. Pechenik 1980, Jespersen \& Olsen 1982, Tooke et al. 1985, Perron 1986, Richmond 1987, Todd \& Havenhand 1988, Jaeckle \& Manahan 1992, Rombough 1994, Moran \& Manahan 2003, Bennett \& Marshall 2005) and these studies provide an estimate of the relative values for the larval energetic parameters in our model, from which we can then test the effects of changing the rank order of these values on the qualitative predictions of the model. We also assume that the energetic cost to larvae during direct habitat exploration in the boundary layer $(\gamma$, Table 1$)$ is likely to be greater than that while feeding in the water column. We hypothesize that this added cost may result from (1) an actual increase in metabolic expenditures in order to penetrate and move about in the boundary layer relative to the water column, (2) a decrease in the amount of food available to larvae while in the boundary layer. It seems likely to us that both of these mechanisms could be operating synergistically, but as with other parameters in the model, we include flexibility in the event that our assumptions prove false. If larval energetic expenditure turns out to be equal to or even reduced in the boundary layer relative to the water column, then the value of $\gamma$ would simply become zero or negative, respectively, in our model (i.e. the additional cost of searching would actually lead to less energy being consumed per unit time by searching larvae).

Finally, we assume that individual expected future reproductive success increases linearly with the energy state of a larva at settlement, minus some fixed minimum cost of metamorphosing $(\varphi$, Table 1$)$. This assumption is based on several lines of evidence that are highly suggestive of this general prediction despite few detailed experimental data from the field (reviewed by Moran \& Emlet 2001, Marshall \& Keough 2005). The first line of evidence comprises a number of studies suggesting that larvae that settle with higher energy reserves can allocate more resources to juvenile feeding structures, attachment, defense, etc., and such carry-over effects could consequently lead to higher juvenile growth or survival rates (e.g. Pechenik 1980, Qian et al. 1990, Moran 1999, Bennett \& Marshall 2005). Although larval mortality is widely acknowledged to be high among marine species, juvenile habitat availability and survivorship may also be an important determinant of settlement decisions (e.g. Eggleston 1995, Gosselin \& Qian 1997, Moran 1999). Finally, this increase in juvenile growth or survival rates should translate into increased fitness because of the oft-cited relationship between increasing body size and reproductive output (e.g. Bertness et al. 1991, Levitan 1991, Toonen \& Pawlik 2001c). However, we found that this assumption had little influence on the results or interpretation of the model output. Using either an increasing or decreasing curvilinear fitness function did not change the qualitative predictions of the model; as long as there is a positive relationship between initial larval energy state and lifetime reproductive success, the predictions of the model remained relatively unchanged. Higher order nonlinear relationships (such as a bell-shaped relationship) may have 
more complicated effects on the fitness and could potentially alter the predictions of our model, although we did not evaluate such effects here.

Thus, for simplicity, we used the linear terminal fitness (TFF) of a larva that chooses to settle with energy state $x$, in habitat $i$, at time $t$ given by:

$$
\operatorname{TFF}(x, i)=\frac{V_{i} x}{\operatorname{MAX}\left(V_{\mathrm{A}} ; V_{\mathrm{B}}\right)} \rho_{i}
$$

where $V_{i}$ is the relative value of habitat type $i$, and $\rho_{i}$ is the probability of surviving to reproduce in habitat $i$ (where A is optimal and B is suboptimal habitat). Given this terminal fitness function, and the assumptions outlined above, it is possible to write an equation that determines the expected future reproductive success of an individual larva at any given time step and energy value:

$$
F(x, t, T)=\operatorname{MAX}\left\{\begin{array}{l}
F(x \alpha+\delta, t+1, T) \rho_{1} ; \\
\left(1-\lambda_{\mathrm{A}} \lambda_{\mathrm{B}}\right) F(x \gamma+\delta, t+1, T)+ \\
\lambda_{\mathrm{A}} \operatorname{MAX}\left\{\begin{array}{l}
\mathrm{TFF}(x \gamma \phi+\delta, A)_{i} \\
F(x \gamma+\delta, t+1, T)
\end{array}\right\}+ \\
\lambda_{\mathrm{B}} \operatorname{MAX}\left\{\begin{array}{l}
\mathrm{TFF}(x \gamma \phi+\delta, B) ; \\
F(x \gamma+\delta, t+1, T)
\end{array}\right\}
\end{array}\right\}
$$

$F(x \alpha+\delta, t+1, T)$ is read as the lifetime fitness of a larvae surviving from time $t+1$ to $T$, given that the larva is currently alive and its energy state $x_{(t)}$ is $x$ minus $\alpha$ units for maintaining itself during the period and plus $\delta$ units from feeding. MAX is shorthand for a maximization operator, which chooses the largest value returned by the entries within a set of braces, which are separated by semicolons. In this equation, each MAX operation represents a virtual decision. The outermost MAX is the decision of whether or not to look for habitat, while the inner MAX operators are the accept/reject decisions for each optimal (A) and suboptimal (B) habitat types. A cartoon of this equation is presented in Fig. 1.

The model is solved iteratively by setting $F(x, T, T)$ to 0 for all integer values of $x$, stepping back one time unit from $T$ to $T-1$, and solving $F(x, T-1, T)$ for all integer values of $x$. If a particular combination of energy gains and losses results in a non-integer future state, the expected reproductive success (ERS) associated with this state is calculated by linear interpolation between the appropriate values in the future ERS vector. After solving for all integer values of $x$, we know which decision will give us the highest expected terminal fitness (TFF), and so this value (max at $T-1$ ) is our new end-point goal to reach from time $T-2$. This process is then repeated until the entire decision matrix has been solved back to $t=0$. The result of this process is a 2-dimensional decision matrix specifying the optimal decision for each combination of $x$ (current energy state) and $t$ (stage of planktonic lifespan) possible across the entire state space (Fig. 2).

Making predictions from this 2-dimensional decision matrix is difficult however. Interpretation of the model output is much simplified by creating a forward Monte-Carlo simulation of a virtual larval behavior, because such forward simulation is directly analogous to an experimental protocol with $\mathrm{N}$ individuals, each assayed for their response to the experimental substrata. Based on the optimal decision matrix generated above, we then simulate a larval settlement experiment analogous to those performed by researchers in the laboratory by running larvae forward through the model and assaying their individual behavioral decisions. We first have virtual parents spawn 10000 randomly generated larvae, with some initial energy distribution (see below). We then run a single individual larva through the decision tree model presented in Fig. 1 to determine what that individual does until accepting a substratum for settlement, based on the

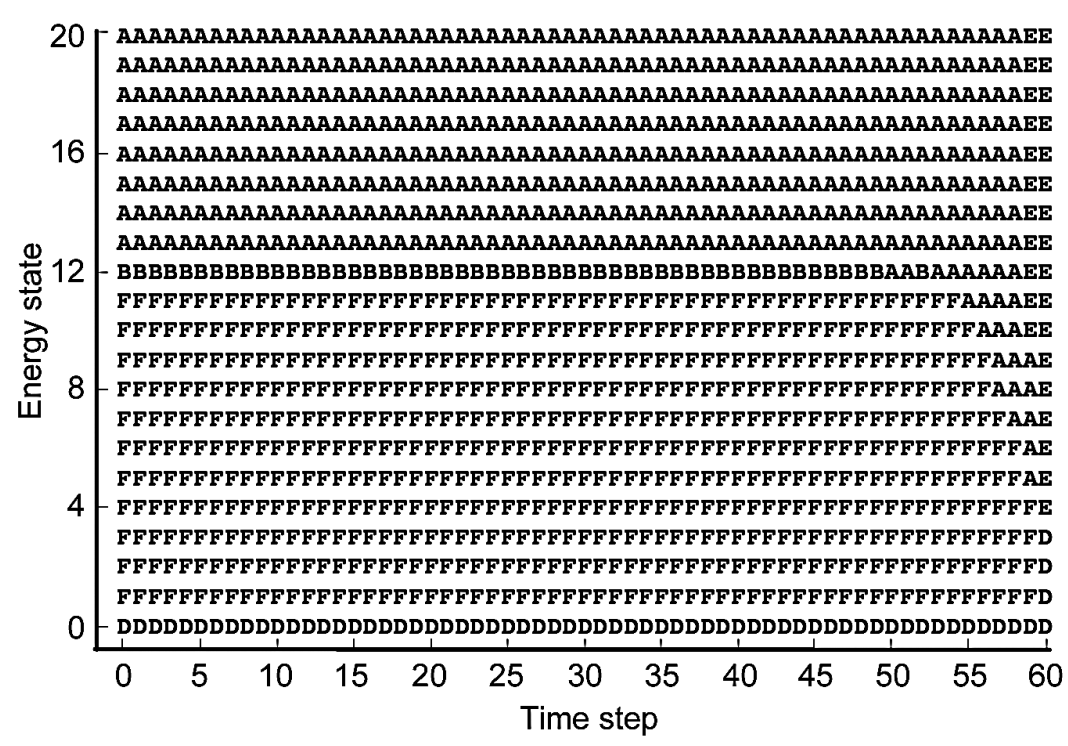

Fig. 2. A decision matrix output from the model, with the maximum fitness benefit across all energy states ( 0 to 20 ) and times ( 0 to 60 ) derived using backward iteration as described in the text. Maximum fitness gain for settlers is realized by settling specifically in response to optimal habitat in locations designated with ' $\mathrm{A}$ ' and from settling in response to suboptimal habitat in areas designated with ' $\mathrm{B}$ '. ' $\mathrm{E}$ ' designates the maximum possible fitness benefit is obtained from accepting any habitat encountered (optimal or suboptimal). ' $F$ ' indicates that larvae should ignore habitat in favor of feeding to maximize their fitness, and ' $D$ ' indicates that larvae have dropped below the minimum energy threshold for successful metamorphosis and therefore died of starvation 
decision matrix generated previously. As each virtual larva moves through the model deciding to feed, search or settle on habitat when encountered, it eventually reaches a point in the decision matrix to accept the substratum it has encountered in the simulation (Fig. 1). The larva is then recorded as having settled on that substratum and the simulation continues until all larvae in that family are assayed for their settlement response. In this way, the model output is generated in a form equivalent to the data generated by an empiricist doing a larval settlement experiment. From each virtual spawn of 10000 larvae, we continued to assay individual larvae until >90\% (at least 9000 individuals) had been recorded as having chosen to settle. At that point, the spawn is considered exhausted, the total number of larvae deciding to accept each substratum type at each time step is written to the disk, and a new virtual spawn is generated in order to be run through the model again. We repeated this forward simulation process for each of 1000 spawns with randomly generated initial energy distributions for the larvae. Thus, each simulation run represents the mean and standard error of the cumulative percentage settlement of the number of virtual larvae metamorphosing in response to optimal and suboptimal substrata from each of 1000 virtual spawns of >9000 settlers each. This simulation design is the closest we could match to the standard experimental protocol used by larval ecologists in their assessment of larval settlement preferences in the laboratory.

We then carried out a sensitivity analysis of the model by varying each parameter in turn across a range of values from 10 to $500 \%$ of the baseline value. Because the greatest changes in the predicted behaviors of larvae are seen around our best-guess parameter values inferred from the literature, we present only the results of 10 to $200 \%$ of baseline for the figures herein. For 2 parameters $\left(\rho_{1}\right.$ and $\left.\rho_{2}\right)$, the upper range was truncated, because values $>100 \%$ are clearly nonsensical for a probability of survival. We fully acknowledge that changing individual parameters sequentially ignores the possibility of complex interactions between parameters; however, the number of possible interactions among all factorial combinations of the model parameters is well beyond the scope of this initial analysis. In order to determine which parameters have the greatest impact on the model predictions, we used 2 different measures of the decision matrix as a function of changes in the parameter values plotted on a proportional scale ( 0 to 1.0 ) as a larval selectivity index. The first measure derived from the decision matrix was the energy state at $t=0$ at which optimal habitat was first accepted (i.e. the energy state at competence). The energy state at which optimal habitat is first accepted indicates the extent to which larvae prefer to remain in the water column feeding, without exploring potential settlement habitats. The second measure was the proportion of the total possible energy state space in which only optimal habitat was accepted. Thus, we have a simple index of larval selectivity across these sensitivity analyses regarding the habitat in which larvae ultimately settle; larvae that accept both optimal and suboptimal habitats at all time points have a selectivity value of zero, while larvae that never accept suboptimal habitat have a value of one.

To determine the effect of initial distribution of larval energy content on predictions from our model, we chose to use the distribution of (1) egg energy contents reported for echinoderms by McEdward \& Chia (1991), (2) egg sizes spawned by females of Hydroides dianthus (Toonen \& Pawlik 2001c), (3) size of H. dianthus larvae at competence (Toonen \& Pawlik 2001c), or (4) a simple random number generator to initialize our virtual spawns. Egg volume appears to be a reasonable proxy for egg energy content among some species, but not for others (e.g. McEdward \& Coulter 1987, McEdward \& Morgan 2001, Allen et al. 2006). Although egg size is of limited value for the quantitative prediction of egg energy content among marine invertebrates (reviewed by Gosselin \& Qian 1998, McEdward \& Miner 2001), we are using this proxy only to generate a distribution of initial larval energy states as a more realistic starting point than some arbitrary distribution. Regardless of which approach we used in our initial runs to generate a distribution of initial larval energy, the qualitative predictions of our model were unchanged. Therefore, for simplicity, we generated a random distribution of initial energetic content with an average value of 10 (50\% of maximum) and a standard deviation of 1 (5\% of maximum) relative energy units in our model.

\section{RESULTS}

In our initial trials, there was little qualitative difference between the decision matrices generated for virtual non-feeding larvae $(\delta=0$, full time dependent decision matrix), and those for feeding larvae $(\delta>\alpha$, stationary strategy only) other than a zone in which feeding larvae chose not to search for habitat in favor of gaining additional energy (Fig. 2). Thus, we present only the results from the stationary strategy model and allow larvae to feed or not in the simulations. To examine the overall fit of our model to real data, we have chosen to use the data set with which we are most familiar, viz. that of the tube-dwelling worm Hydroides dianthus. For $H$. dianthus, optimal substratum is live conspecific adults, and suboptimal habitat is un- 
inhabited, biofilmed hard substratum (Toonen \& Pawlik 1994, 1996, 2001a,b,c). The predictions generated from our model are overlaid on the empirical data for $H$. dianthus in Fig. 3. Our best guess at model parameter values based on averages derived from the literature yielded a reasonable fit to the empirical data, and by simply increasing the cost of metamorphosis, the model fit to the data was surprisingly good (Fig. 3). Below, we examine the effects of each parameter in the model individually, with all other values maintained at the default values we chose originally (Table 1).

\section{Overall sensitivity analysis}

We discuss the model parameters in 3 categories: (1) habitat availability and quality parameters, (2) energetic parameters, (3) mortality risk parameters. One of the most striking results from our model is the relatively narrow range of parameters over which the larval selectivity index (i.e. the proportion of the decision matrix in which larvae will accept optimal relative to suboptimal habitats) changes dramatically (Figs. 4, 5 \& 6). In all cases, changes in parameters either showed relatively little effect on larval selectivity overall (e.g. $\lambda_{\mathrm{B}}$ in Fig. 4A), or resulted in a radical change in larval selectivity across a comparatively narrow range of parameter values around our best-guess estimate derived from the literature (e.g. $\lambda_{\mathrm{A}}$ in Fig. $4 \mathrm{~A}$ ). We could not find any cases in which selectivity changed slowly and consistently across the sensitivity analyses for any parameter in the model (Figs. 4, 5 \& 6).

The willingness of larvae to remain in the water column to feed is generally unaffected by variation in the availability and quality of the 2 habitat types; larvae nearly always start searching for habitat when their energy state exceeds approximately $50 \%$ of the maximum energy attainable (Fig. 2). However, the relative value of each habitat and abundance of optimal habitats has a strong influence on whether or not suboptimal habitat is accepted once larvae start

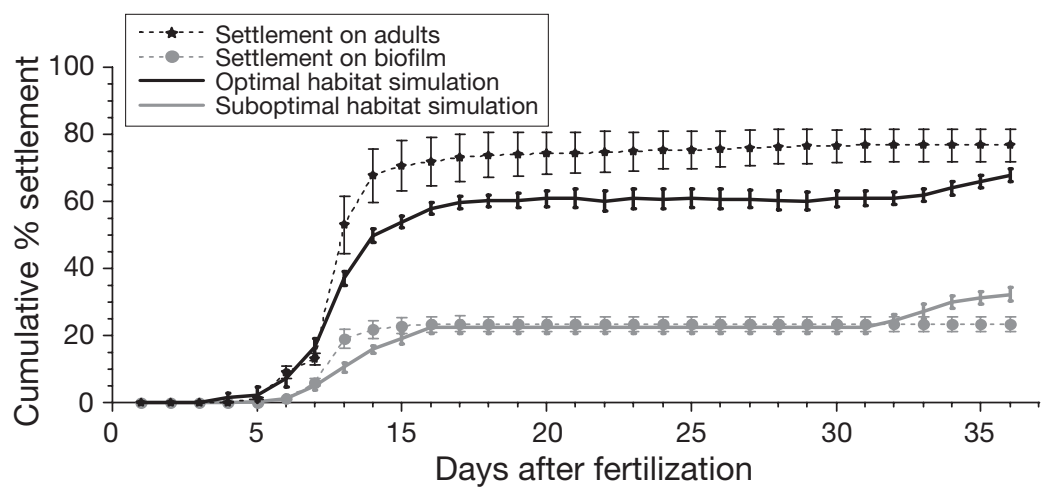

Fig. 3. Comparison of forward iteration virtual larval settlement based on default model values with experimental larval settlement data for the polychaete worm Hydroides dianthus observed in the study of Toonen \& Pawlik (1994). In this simulation, adults are the optimal habitat, and biofilm the suboptimal habitat
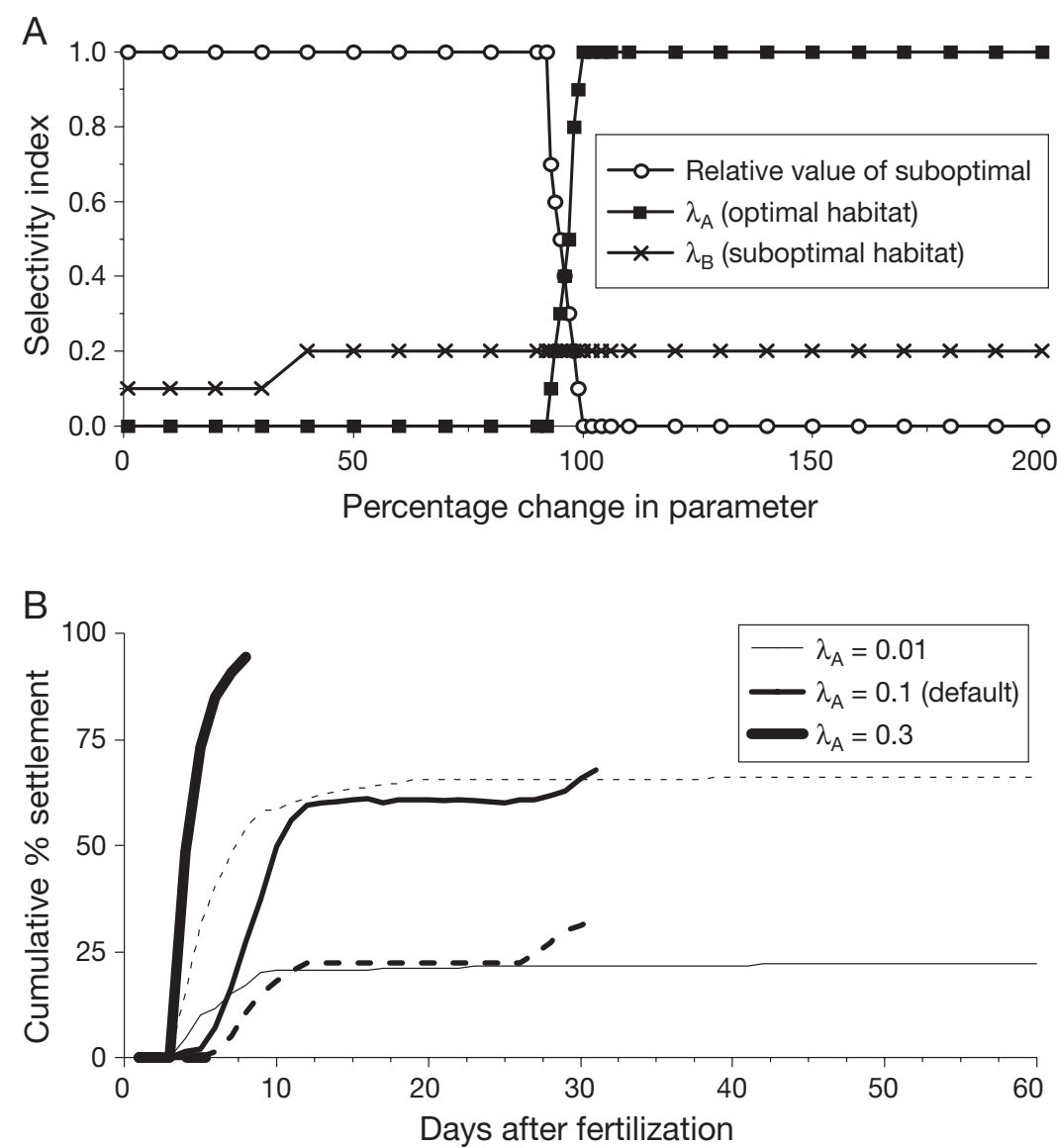

Fig. 4. (A) Change in larval selectivity (i.e. proportion of states in decision matrix in which only optimal habitat is accepted) in simulations as a function of changes in the habitat parameters. All other parameters in the model are maintained at default values (Table 1). (B) Simulated settlement trajectories for selected values of $\lambda_{\mathrm{A}}$ (the probability of encountering optimal habitat while searching) around the default to illustrate the effects of altered larval selectivity index on predicted settlement patterns of larvae. Continuous lines represent settlement on optimal substrata, dashed lines are acceptance of suboptimal habitat; simulations were terminated at the time step in which $>90 \%$ of larvae accepted a habitat for settlement 

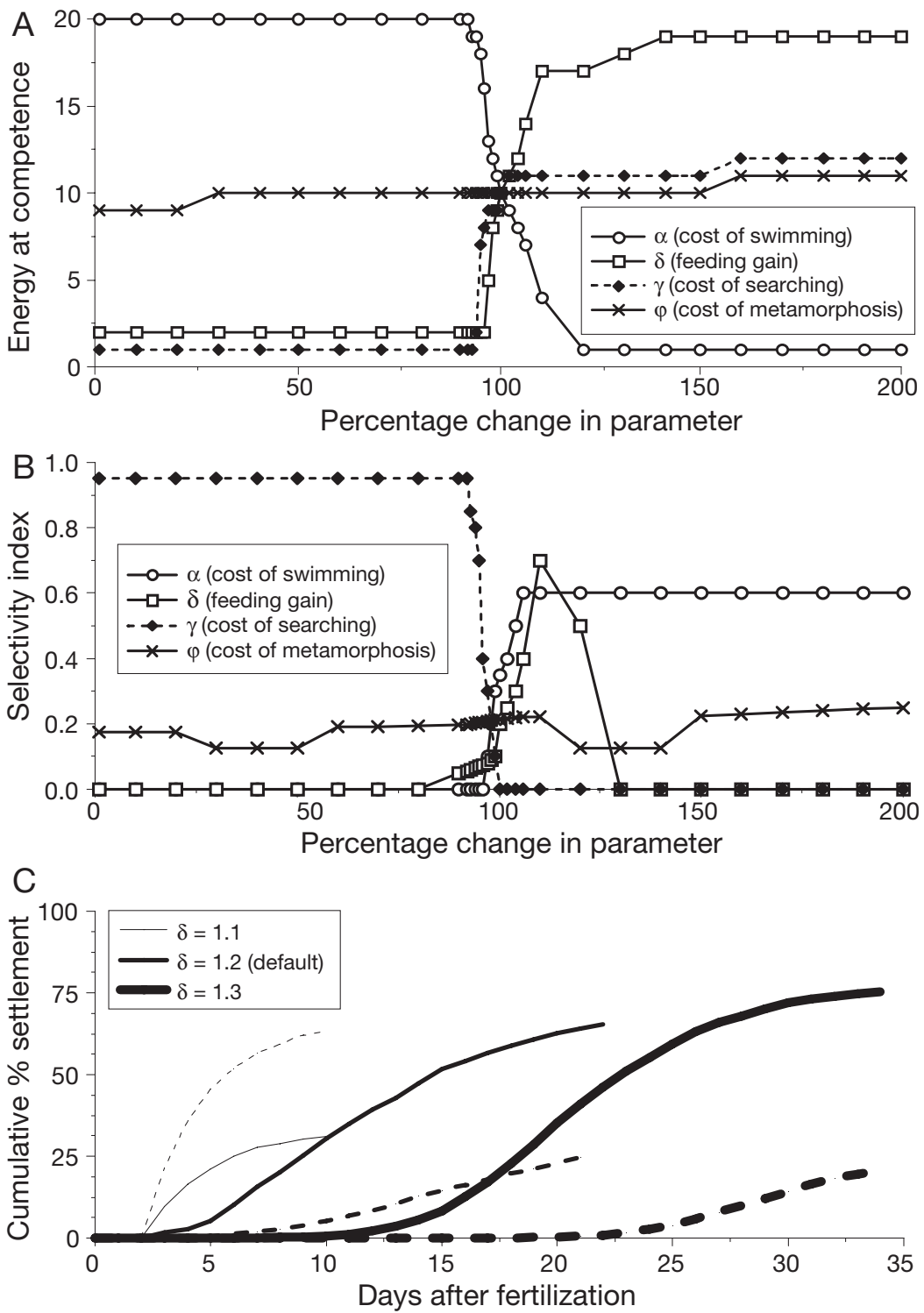

Fig. 5. (A) Energy state of larvae at competence as a function of variation in energetic parameters in the model. (B) Change in larval selectivity in simulations as a function of changes in the energetic parameters of the model. All other parameters in the model are maintained at default values (Table 1). (C) Simulated settlement trajectories for selected values of $\delta$ (the energetic gain from feeding) around the default to illustrate the effects of altered larval selectivity index on predicted settlement patterns of larvae. Continuous lines represent settlement on optimal substrata, dashed lines are acceptance of suboptimal habitat; simulations were terminated at the time step in which $>90 \%$ of larvae accepted a habitat for settlement

searching (Fig. 4). Increasing the relative value of suboptimal habitat decreases selectivity; larvae cease to be choosy altogether when suboptimal habitat provides roughly the same expected reproductive success as optimal habitat ( $>86 \%$ at default values in our simulations). In contrast, larvae always reject suboptimal habitat if the relative fitness payoff is too far below that of optimal habitat (Fig. 4). For species with highly spe- cific post-settlement habitat or food requirements, the value of suboptimal habitat may approach zero if such requirements are not present (e.g. Botello \& Krug 2006), and larvae in such cases are predicted to settle only in response to optimal habitat in our simulations. Increasing the availability of optimal habitat increases selectivity, and suboptimal habitat is rejected under all states once optimal habitats are at least equally as common as suboptimal ones. At the other end of the scale, larvae in our model accept suboptimal habitat with increasing frequency when optimal habitats become so rare that most larvae will not encounter them during their maximum pelagic lifespan.

The energetic parameters have the strongest effect on the energy state at competence (Fig. 5). As the value of feeding $(\delta)$ goes down, or the cost of remaining in the water column $(\alpha)$ goes up, the energy state at which larvae decide to start searching drops rapidly. Similarly, if the additional energetic cost of searching $(\gamma)$ drops, then larvae choose to begin searching sooner as well. The energy state at competence is least sensitive to variation in the cost of metamorphosis $(\varphi)$, as the energy state increases only marginally while cost of metamorphosis ranges from 5 to $200 \%$ of the baseline value (Fig. 5A). The degree of selectivity also varies with changes in energetic parameters (Fig. 5B), but the interpretations of these changes are more difficult because of the strong variation in energy state at competence. The cost of metamorphosis has a relatively small influence; larvae are slightly choosier when the cost of metamorphosis is high because they lose more energy during the process. As energetic gain from feeding increases, selectivity first increases as expected but then decreases sharply with unlimited food ( $\delta$ increased by $130 \%$ or more, Fig. 5B). This decrease in selectivity with unlimited food only makes sense when combined with the observation that at very high food availability larvae always feed until they reach the maximum possible energy state before beginning to search for habitat. In this case, the fitness gain from settling with surplus energy in suboptimal habitats compensates for the difference in fitness 

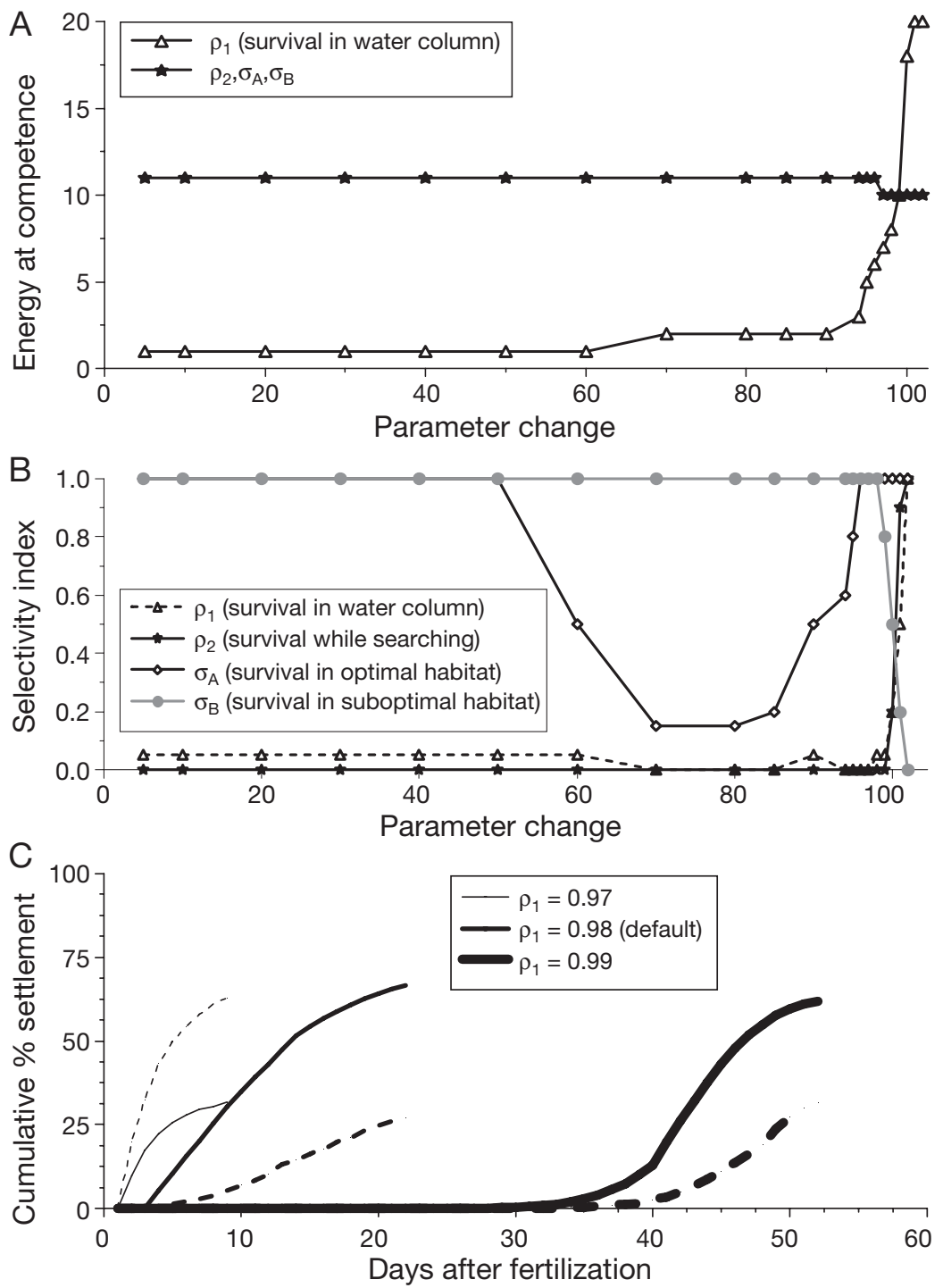

Fig. 6. (A) Energy state at competence as a function of variation in survival probabilities while feeding in the water column $\left(\rho_{1}\right)$, searching for suitable substrata for settlement $\left(\rho_{2}\right)$, survival to successful reproduction in optimal $\left(\sigma_{A}\right)$ and suboptimal habitats $\left(\sigma_{B}\right)$. (B) Larval selectivity index as a function of variation in the probability of survival per time step in the simulations. (C) Simulated settlement trajectories for selected values of $\rho_{1}$ (the probability of survival per time step while feeding in the water column) around the default to illustrate the effects of altered larval selectivity index on predicted settlement patterns of larvae. Continuous lines represent settlement on optimal substrata, dashed lines are acceptance of suboptimal habitat; simulations were terminated at the time step in which $>90 \%$ of larvae accepted a habitat for settlement

between optimal and suboptimal habitats. Thus, larvae are most choosy when the cost-benefit ratios change, because the cost of searching $(\gamma)$ decreases, or the cost of remaining in the water column $(\alpha)$ increases (Fig. 5B). This last point seems counterintuitive, however similar results are reported by Stamps et al. (2005) in a general model of habitat selection and the finding seems to be a robust result from completely different modeling approaches.
The probability of survival has a strong effect on larval willingness to prolong their search for optimal substrata, but little effect on the selectivity index (i.e. their preference for the optimal habitat if encountered). Larvae are more willing to remain in the water column feeding or searching for habitat if the likelihood of surviving there is high. Thus, both the selectivity index and energy state at competence increase as survival in the water column increases (Fig. 6). In contrast, only larval selectivity responds to changes in the probability of survival while searching, but the sensitivity there is similar in magnitude and direction to that for survival in the water column (Fig. 6).

\section{Probability of finding habitat $\left(\lambda_{i}\right)$}

We describe habitat availability in terms of the probability of encountering that habitat type when a larva decides to search for a site for settlement; the more common a given habitat type, the more likely that larvae will encounter that substratum on any given search attempt. Habitat availability proves to be a strong determinant of larval decisions on whether or not to accept optimal or suboptimal substrata in our model. Our default parameter values set the probability of encounter with suboptimal substratum at twice that of optimal habitat, which may be far lower than reality in many systems. The qualitative predictions of the model are relatively robust to variation in habitat encounter probabilities until the probability of encounter for optimal substratum reaches more than $30 \%$ per time increment, at which point all competent larvae quickly become highly selective (Fig. 4). We could not accomplish the converse pattern (all larvae settling in response to suboptimal habitat) either by making suboptimal substrata incredibly common (95\% encounter probability per time step) or by making optimal habitat incredibly rare (1\% encounter probability per time step). Although it is possible to alter larval selectivity through variations in habitat availability (Fig. 4A), larvae always accepted optimal habitat when encountered, and the reduced larval selectivity from making optimal habitat very rarely 
results in larvae accepting habitats in the frequency at which each is encountered in the environment (Fig. 4B). This result derives from the fact that as encounter with either habitat type becomes rarer, the decision to accept each habitat type is a direct function of the expected fitness payoff from that habitat type. The greater the difference in the fitness payoff between the habitats (e.g. habitat specialization), the rarer the optimal habitat must be in order for larvae to settle on suboptimal substratum (data not shown).

\section{Energetic gain from feeding $(\delta)$}

Energetic gain from feeding has a strong effect on larval planktonic duration, but little to no effect on individual larval preference for each habitat type. However, changes in the duration of larval planktonic period resulting from feeding can affect the settlement patterns of larvae in our simulations. If the gain from feeding is very low, larvae tend to settle early in the competent period, and this greatly reduces the time available to search for optimal habitat. For non-feeding larvae, the metabolic costs of swimming or substratum assessment will always exceed the gain from larval feeding (which is zero for true non-feeding larvae), and may also occur due to food limitation or other stresses among feeding larvae. Under these conditions, the entire spawn of larvae settle comparatively quickly on either substratum at roughly the rate of encounter in the model (Fig. 5). This prediction stems from the fact that larvae obtain little from a prolonged planktonic period other than increased exposure to planktonic mortality risk, and larvae accept either habitat when the payoff from suboptimal habitat approaches the risk of searching for optimal habitat (i.e. the desperate larva hypothesis).

Among those larvae that can eat, energetic gain from feeding is likely to vary through time and space, and may prove to be an important determinant of individual larval settlement decisions. As we allow the energetic gain from feeding $(\delta)$ to exceed the total metabolic costs of swimming and habitat assessment, the planktonic larval stage typically becomes prolonged (Fig. 5). This prolongation also leads to a shift in the proportion of larvae settling in response to each substratum, i.e. larvae cease to settle in direct proportion to the habitat encounter rate, and begin to accept primarily optimal habitat (Fig. 5). However, this settlement switch is not related to individual preferences (i.e. in both cases the decision matrix itself remains unchanged, and larvae prefer to settle in optimal habitats when they encounter them); rather, changes in energetic parameters tend to constrain larvae to a different section of the state space in the decision matrix. In this case, the differences in settlement on optimal and suboptimal substrata are not due to changes in the habitat preference, but rather to the unwillingness of larvae to return to the water column when they encounter habitat, and the probability of encounter with each habitat type within a given time period. Thus, it is really the duration of the planktonic period that affects proportions of larvae settling in optimal and suboptimal habitat, rather than a change in the individual preferences of larvae for a given habitat type. Overall, the reduced settlement in response to optimal substrata when metabolic gain from feeding is lower than the energetic cost of prolonging the search results from larvae being unwilling to continue searching, and the pattern of settlement reflects the probability of competent larvae encountering optimal habitat within the planktonic period (Fig. 5). When the preferred habitat is limited (i.e. there is less than a $100 \%$ chance that larvae will encounter the habitat within the planktonic period), then reduced search times make it far less likely that larvae will encounter and be able to accept the optimal substratum.

\section{Energetic cost of metamorphosis $(\varphi)$}

The cost of metamorphosis has no qualitative effect on either the selectivity of larvae or the mean length of the planktonic period. Changes of several orders of magnitude (0.01 to 10 ) did not result in any difference in the cumulative proportion of larvae settling in response to either substratum type (Fig. 5). Rather than showing any effect on the behavior of competent larvae, the energetic cost of metamorphosis shows a precompetent effect, viz. the higher the cost of metamorphosis $(\varphi)$, the longer the precompetent feeding period required for larvae to accumulate sufficient resources to complete metamorphosis successfully. This cost of metamorphosis itself has no real effect on settlement patterns of larvae in these simulations, and it is only the ratio of the initial energetic provisioning of the larvae relative to the energetic requirement for larvae to complete metamorphosis that results in changes to the pattern of larval settlement predicted by our model. An iterative fit of the model results to actual settlement data for Hydroides dianthus (Toonen \& Pawlik 1994, 2001b) suggests that a value of roughly 4 times the initial energy provisioned to the larvae is required for successful metamorphosis in this species, although this result is unlikely to be general across species (e.g. Allen et al. 2006). However, if we assume that egg and larval sizes are well-correlated with their energetic content, an assumption which appears reasonable for some species, (e.g. McEdward 
\& Chia 1991), but not for others (e.g. McEdward \& Coulter 1987), the size differences between competent larvae and fertilized zygotes suggest that our iterative fit to the true metabolic cost of metamorphosis is reasonable for $H$. dianthus. Using sizes of the eggs and larvae of $H$. dianthus reported from previous work (Toonen \& Pawlik 2001c) as a proxy for energy content, competent larvae $(\sim 300 \mu \mathrm{m})$ are almost exactly 4 times the size of fertilized embryos $(\sim 75 \mu \mathrm{m})$. Although this relationship between body size and energy content in $H$. dianthus remains untested, the cost of metamorphosis parameter from the initial default values chosen gives a remarkable fit to the empirical data presented for this species from earlier studies (Fig. 3).

\section{Metabolic cost of swimming/searching for habitat $(\gamma)$}

As with the energetic gain from feeding, the metabolic cost of swimming and searching for preferred habitat affects the relative proportion of larvae settling in each habitat indirectly through a strong effect on mean planktonic lifespan. Likewise, metabolic cost shows no direct effect on individual larval selectivity. A change of several orders of magnitude leads to no difference in the individual settlement preferences of larvae (the decision matrix is virtually unchanged), but could result in significant differences in the relative proportion of larvae settling in response to each substratum through time (Fig. 5).

Among non-feeding larvae, this parameter directly impacts the potential length of the planktonic lifespan by determining how quickly larvae use their available energy reserves. In feeding larvae, however, it is the ratio of the gain from feeding to the metabolic cost that determines whether larvae in the water column are gaining or losing energy with each time step. If the cost of searching for habitat exceeds the energetic gain from feeding, then larvae lose energy with each time step, and are likely to settle early in the planktonic period (Fig. 5). Conversely, when the cost of searching is less than the energetic payoff from feeding in the water column, larvae can chose to feed rather than search for settlement substrata, and accumulate additional energy reserves. In this latter case, larvae tend to delay metamorphosis in favor of accumulating surplus energy reserves to devote to post-metamorphic growth and defense such that they maximize the potential lifetime fitness expectation of a given habitat choice (Fig. 5). Overall, the primary effect of altering the metabolic cost of searching for suitable habitat is through the duration of the planktonic period, rather than the settlement preferences of larvae (the decision matrix remains unchanged).

\section{Mortality parameters $\left(\sigma_{i} \& \rho_{i}\right)$}

We first discuss the effect varying the probability of survival through successful reproduction in optimal $\left(\sigma_{\mathrm{A}}\right)$ or suboptimal $\left(\sigma_{\mathrm{B}}\right)$ habitats after settlement. The lower the probability of survival through successful reproduction, the more the expected fitness payoff (TFF) for acceptance of that habitat type is discounted. As the probability of survival in optimal habitats decreases, larvae become more accepting of suboptimal habitats (i.e. the selectivity index drops) until such point that the payoff in 'optimal' habitats becomes lower than that in 'suboptimal' habitats (i.e. the fitness consequences in the 2 habitats are reversed), and selectivity rapidly increases again (Fig. 6), but for the opposite habitat type. The expected fitness payoff after settlement is a product of both survival probability and future reproduction in the habitat of choice; thus, because the terminal fitness payoff for optimal habitats is higher, the probability of survival through successful reproduction had to be halved before the habitat payoffs switched and larvae ceased accepting optimal habitat in our simulations. In contrast, because the fitness payoff of suboptimal habitats is already reduced relative to the optimal substratum, as the survival probability in suboptimal habitats decreases, the fitness payoff is similarly reduced such that larvae quickly stop accepting suboptimal habitats (Fig. 6). Thus, for species with specific habitat requirements such that settlement in suboptimal habitat has a very low probability of survival, the model predicts that larvae should not accept alternate habitat. For a more detailed examination of this region of parameter space, we refer readers to the recent work of Elkin \& Marshall (2007) who consider the issue of habitat choice by hostdependent species explicitly.

Contrary to intuition and the general expectation in the field, mortality rate of larvae in the water column $\left(\rho_{1}\right)$ or while assessing substratum suitability $\left(\rho_{2}\right)$ appears to have little direct effect on the larval settlement preferences (i.e. the decision matrix is unchanged) in the model. This result was surprising to us given the significance placed on mortality in most discussions of habitat selection, both empirical and theoretical, in the field (e.g. Levins \& MacArthur 1969, Doyle 1975, Ward 1987, Rumrill 1990). However, across natural estimates of larval mortality (reviewed by Rumrill 1990: 0.03 to $0.8 \mathrm{~d}^{-1}$ ), the probability of planktonic survival had a dramatic effect on only the duration of the larval period, not larval selectivity (Fig. 6). Like the energetic parameters discussed previously, the higher the instantaneous mortality rate in the water column, the more likely larvae will settle early in the competent period, but the relative preference of larvae for each substratum type (as reflected in 
the decision matrix) is completely unaffected. Ultimately planktonic larval survival rates have virtually no effect on the decision matrix, but can still have a strong effect on the proportion of larvae settling in each habitat type as a result of their willingness to remain in the plankton and continuing to search for alternate habitats (Fig. 6). Regardless, the primary effect of increased larval mortality that emerges from the model is on planktonic duration rather than individual settlement preference reflected in the decision matrix; thus, changes in the percentage settlement in the simulations are very similar to any of the energetic parameters that have an equal impact on pelagic larval duration (e.g. compare Fig. 5C to 6C).

Overall, the effect of planktonic mortality is relatively weak, with the greatest change in larval selectivity occurring between 100 to $96 \%$ survival per time step, beyond which larvae show no change in the selectivity index across the remainder of parameter space (Fig. 6). Once the instantaneous mortality becomes high enough that larvae typically die if they reject a substratum prior to encountering another, then larvae begin to accept any habitat encountered, because the payoff (no matter how low) is better than none (Fig. 6). The instantaneous mortality rate estimates we could find from the literature provided planktonic survival probabilities of roughly 20 to $97 \%$ per day. Even across this broad range of planktonic mortality rates, the results of our model are robust; planktonic larval mortality should affect primarily larval duration rather than larval settlement preference (as reflected in the decision matrix) for either feeding or non-feeding larvae. Although this result may seem surprising to many, Stamps et al. (2005) report a similar finding for their general model of habitat choice during dispersal; the convergence of results among highly divergent models and modeling techniques suggest that, contrary to intuition, larval mortality risk may in fact have very little impact on larval habitat preferences at settlement.

\section{Maximum number of time steps $(T)$ and energetic state $(C)$}

Neither the maximum number of time steps incorporated into the model nor the maximum energetic state had any qualitative effect on the ultimate proportion of larvae settling in response to each substratum across any of the parameter manipulations discussed previously. The shape of the cumulative percentage settlement curves was similar for changes to either parameter, and the results did not differ across an increase of 2 orders of magnitude for either the maximum number of time steps included in the model or the maximum energetic state (data not shown).

\section{DISCUSSION}

Understanding how and why larvae tend to settle in certain areas and whether or not those settlement preferences control adult distributions remains a central focus of much marine ecology (reviewed by Gaines \& Roughgarden 1985, Hairston 1989, Menge 2000). Our model is the first individual-based model to examine larval settlement preferences and to consider the role of state-dependent decisions for individual settlement choices. While we believe that our model could be easily expanded for any number of alternate settlement substrata, in this initial attempt, we have chosen to model the settlement decision between only 2 substratum options, i.e. an optimal and a suboptimal settlement choice. Even with only 2 alternatives, this framework is flexible enough to consider cases of extreme larval specificity (fitness in the suboptimal habitat is zero) to extreme habitat generality (fitness in all habitats is equal). Likewise, our predictions are unchanged and even more general if the suboptimal habitat type is considered as an average of many alternative substratum choices as opposed to one, although we acknowledge that greater complexity may reveal non-intuitive predictions that we have not considered here.

Within this simplistic framework, we can then look at the relative costs and benefits of settlement decisions given the current state of the larva, and make falsifiable predictions about the effect of the parameters we model here on larval settlement behaviors. The most fundamental difference among the larvae that we try to simulate herein is whether or not they are able to feed in the water column. For feeding (planktotrophic) larvae that experience patchy food resources in the water column, it may be difficult to detect the imminent end to their planktonic lifespan. For cases in which larvae have an imperfect ability to predict the end of their pelagic existence, the time-independent (stationary) strategy is likely to be the most appropriate model, because they cannot predict the amount of time remaining to them in which to search for alternate habitats. On the other hand, it seems intuitive that nonfeeding (lecithotrophic) larvae, which carry their provisions in the form of yolk reserves, ought to be capable of detecting that their yolk reserves are depleted and that their planktonic lifespan will therefore shortly come to an end. In those cases where larvae have a reliable estimate of the time remaining to them in which to search for suitable settlement substrata, the fully time-dependent model is more appropriate for these simulations. However, there is now good experimental evidence that some feeding larvae are capable of altering their settlement specificity depending on their energetic status (e.g. Marshall \& Keough 2003, Allen et al. 2006, Botello \& Krug 2006). Further varia- 
tion among species comes from the fact that some lecithotrophic larvae may be able to increase their current energetic state through facultative feeding (e.g. Emlet 1986). However, it has also been suggested that invertebrate larvae may have a genetically determined endpoint to their planktonic lifespan, and that the ability to delay settlement is a function of the speed at which larvae progress through the developmental program (e.g. Pechenik 1980). If this latter hypothesis is true, then the fully-time dependent model is more appropriate for these simulations regardless of whether larvae are capable of feeding in the water column or not. Although this issue remains unresolved currently, this uncertainty does not impact our ability to generate testable hypotheses from this model. Likewise, a heritable component to larval selectivity (Toonen \& Pawlik 2001a, Botello \& Krug 2006) does not negate these predictions; to the contrary, our model assumes that variation in larval settlement choices are adaptive, and therefore requires that the basis of such behaviors is in fact heritable and available to selection. In the case of the polychaete Hydroides dianthus, there is clear evidence that larval selectivity has a heritable genetic component (Toonen \& Pawlik 2001a), and that differences in larval settlement among several larval size classes were not different (Toonen \& Pawlik 2001c); however, these experiments were quite coarse and did not examine the interaction between genetic background, prior experience and energy content of individual larvae explicitly. In experiments with the opisthobranch Alderia sp., Botello \& Krug (2006) demonstrated that settlement choice depends critically on interactions between the genetic background, prior experience and energy content of a given larva. However, despite the extreme feeding specialization of Alderia, some variable proportion of each clutch metamorphosed spontaneously within $2 \mathrm{~d}$ of hatching, and a low percentage ( 0 to $9 \%$ ) also settled in response to alternate substrata or filtered seawater controls in these experiments (Krug 2001). Thus, even in cases where settlement preference is heritable and larvae may have a genetic predisposition to settle in response to optimal habitat, the final settlement choice appears somewhat plastic, and individual behavior can likely be modified in response to experience and current condition as predicted by our model.

In large part, however, the developmental mode and the particulars of whether or not larvae can reliably predict the end of their planktonic lifespan make little difference to the overall predictions from our simulations. This is because although these details impose limitations on the possible range of values each parameter can realistically assume, our simulations are most impacted by the relative values of each of the parameters in respect to one another, and our sensitiv- ity analyses attempt to cover the majority of parameter space in the model. Thus, there is considerable overlap in the predictions generated from the model for how each group should respond to optimal and suboptimal substrata. For example, there may be some species of feeding larvae that appear to 'keep an eye on the fuel gauge' and settle less selectively or in response to lower cue doses when food reserves become low (e.g. Marshall \& Keough 2003, Botello \& Krug 2006); in such cases, these larvae behave more similarly to non-feeding larvae in our model, and the fully time-dependent version would be more appropriate than the stationary strategy we have used for species with feeding larvae. Such overlap in the ability to predict the end of planktonic life may help to explain the variability reported in the literature with regards to how feeding larvae respond to bouts of starvation; some species respond by reverting to a pre-competent state until feeding is resumed (e.g. Pawlik \& Mense 1994, Toonen \& Pawlik 2001c), whereas other species retain competency and begin to settle rapidly in response to starvation (e.g. Eckert 1995, Pechenik et al. 1996, Marshall \& Keough 2003, Botello \& Krug 2006). If bouts of low food availability are rare or highly ephemeral in the developmental period of feeding larvae, we would expect that waiting it out may be a much better strategy on average than larval desperation. On the other hand, if low food availability is (1) common during the developmental period, (2) tends to be sufficiently long-lasting, or (3) reduces the likelihood of encountering favorable substratum, such that waiting it out proves maladaptive, then we would expect feeding larvae to respond to starvation in the same way as non-feeding larvae that have exhausted their yolk reserves. The variability of responses reported in the literature is in accord with the model prediction, and our model could be expanded or modified to consider alternative hypotheses for variability in larval selectivity (e.g. Bishop et al. 2006).

Previous models of larval settlement and life-history theory predicts that there must be trade-offs between egg size, number of offspring and precompetent stage duration (Vance 1973a,b, Doyle 1975, Christiansen \& Fenchel 1979, Caswell 1981, Grant 1983; see review by Strathmann 1985). We see little overlap between our model and earlier theoretical work, because we are considering an issue fundamentally different from those of these earlier studies. The only pre-competency effect that we see in our modeling results from an increase in the energetic cost of metamorphosis (Fig. 5). In other words, the greater the cost of metamorphosis, the greater the provisioning that is required from the parents, or the longer the larvae must feed in the water column before they gain the energy reserves necessary to complete development 
and metamorphose successfully. However, the precompetent period appears to have no obvious effect on larval selectivity that we can detect with our model. Therefore, our efforts focus specifically on the competent period of larval development and the contextdependent decisions that a larva must make when faced with accepting or rejecting a substratum encountered during planktonic dispersal.

The single most significant result that emerges from these simulations is that larvae must have a reasonable chance of not finding the optimal habitat in order for there to be any expectation of variable settlement preferences. If larvae have a fixed and predictable planktonic period, and habitat is limited, then our model returns the same predictions as generalized models of habitat selection by dispersers, i.e. when individuals are faced with a limited time horizon, the threshold of habitat quality they are willing to accept should almost always decline as they approach the end of their search opportunity (reviewed Stamps \& Krishnan 2005, Stamps et al. 2005). However, if habitat encounter rates are sufficiently high that individual larvae encounter all the possible habitat types once or more within the average planktonic period, or if the payoff from suboptimal habitat is sufficiently low, then the model predicts that larvae should have fixed settlement responses to substrata, and none should accept suboptimal habitat (Fig. 4). This prediction agrees with experimental work on the sea slug Alderia sp. (Botello \& Krug 2006) and a theoretical consideration of the optimal settlement choices of larvae in cases of habitat specialization (Elkin \& Marshall 2007). Unlike our model which makes an effort to be general, the model of Elkin \& Marshall (2007) deals specifically with settlement preference of species with habitat specialization, so we leave detailed discussion of that portion of parameter space to them.

In the absence of such strong habitat specialization, once encounter rates for the optimal habitat have decreased to the point that some larvae complete the planktonic period without ever encountering the optimal habitat, then our model predicts that selection should result in larvae having variable settlement preferences. In this case, it would be adaptive for larvae to be plastic in their response to settlement cues, such that they are capable of deciding to accept alternate settlement substrata or continue to search based upon their current energy reserves and the substratum that they have located; state-dependent variability among individual settlement preferences should be strongly favored by natural selection. Thus, if larvae can search indefinitely or encounter suitable substrata at such a high rate that every individual on average encounters all the alternative substrata possible, there should be no variability among larvae, all larvae should have fixed responses to substrata, and should respond to substratum-derived cues in the same manner. In the simplest terms, variable settlement responses are only advantageous in cases where the search duration is limited or the preferred habitat is sufficiently rare that on average some individuals will always have to make a choice to accept an alternative substratum by the end of their planktonic period.

The other major result of these simulations is that many of the parameter values do not have a direct impact on individual larval preference reflected in the decision matrix, but instead constrain larvae to a restricted portion of that decision matrix by decreasing the mean planktonic duration. That is not to say that they do not have an effect on the proportion of larvae that settle in response to optimal and suboptimal habitats (Figs. 4, 5 \& 6). In other words, larvae would make the same decision under the same conditions if given the chance (Fig. 2), but specific sets of parameter values (feeding, cost of metamorphosis, mortality, etc.) prevent the majority of larvae from ever reaching those portions of the decision matrix before encountering an acceptable habitat in the forward iteration simulations. For many marine species, there is an obvious and significant cost to delaying metamorphosis (e.g. Highsmith \& Emlet 1986, Victor 1986, Pechenik \& Rice 2001, Bennett \& Marshall 2005), and the duration of the planktonic period cannot be prolonged without consequences (reviewed by Pechenik 1990, Pechenik et al. 1998). Consistent with this prediction, the greatest impact on larval settlement patterns in our simulations comes from an indirect effect on selectivity via a direct effect on larval planktonic period. Specifically, individual settlement preferences in the decision matrix generated for each set of parameter values can be quite similar or completely unchanged, but can still result in greatly reduced search durations, altered habitat encounter rates and acceptance rates for optimal and suboptimal habitats as a result (Figs. 4, 5 \& 6). Our simulations suggest that some of the most obvious candidate parameters for influencing larval settlement behaviors (such as the probability of encountering suitable substrata, planktonic mortality rate, metabolic costs, and energetic gain from feeding) ultimately had little effect on the decision matrix for larvae. These parameters instead reduce the mean planktonic period, and allow larvae to visit only a restricted portion of the decision matrix in the simulations; the result is a qualitative shift in the proportion of larvae settling in response to each substratum across the range of tested parameter values, but no alteration of the substratum preferences of individual larvae in the simulation. This distinction is important, because traditional no-choice larval settlement experiments may miss this effect. Thus, our results predict that, regardless of 
developmental mode or habitat types considered, factors which alter the planktonic period available for individual larvae to search for habitat should have the greatest impact on the ultimate patterns of settlement in the field.

It is particularly noteworthy that despite the emphasis placed on planktonic mortality rate in the literature (reviewed by Rumrill 1990), we can detect little direct effect of larval mortality rate on the individual settlement preferences of competent larvae as measured by the decision matrix. The most obvious effect of planktonic mortality is to reduce pelagic duration of larvae in simulations. In fact, any parameter combinations which reduce the mean planktonic period equivalently to high planktonic mortality also show a similar effect on settlement patterns in our simulations (e.g. compare Figs. 5C \& 6C), suggesting that planktonic mortality rate may be overemphasized in importance. Similarly minor effects of mortality during dispersal were found in the general models of habitat choice by dispersers recently published by Stamps \& Krishnan (2005), Stamps et al. (2005) and Stamps (2006).

Our results further suggest that all else being equal, there are conditions in which larvae can actually maximize their expected lifetime fitness by accepting substrata that may otherwise appear suboptimal. Even in the case of Hydroides dianthus, for which there is good evidence of a heritable genetic component of larval settlement preference, our model predicts some plasticity among competent larvae in response to habitat, depending on the conditions under which larvae encounter that habitat type. Although there are now good general models of habitat choice for dispersers (e.g. Stamps et al. 2005), and several recent studies have recognized the importance of considering individual variability in larval settlement behaviors (e.g. Raimondi \& Keough 1990, Toonen \& Pawlik 2001a), this is the first study to consider explicitly the specific energetic state of an individual larva and the conditions under which it finds itself when encountering habitat to determine what is the optimal settlement choice for that particular individual under those conditions. The model presented here is clearly only the first tentative step in this process, but it makes falsifiable predictions about the range of conditions under which larvae should be choosy and those conditions under which larvae should be accepting of alternative habitats. Although our model is clearly limited in scope, the general approach employed and the parameters of interest should be applicable across a wide range of larval settlement choice systems, and probably apply to generalized cases of habitat choice by other dispersers as well. We argue that settlement of marine invertebrate larvae should be considered in the same rigorous conceptual framework as animal behaviorists use to assess habitat choice (reviewed by Stamps \& Krishnan 2005, Stamps 2006), and this is a first attempt to provide such a conceptual framework for future study. We are especially encouraged that our results coincide remarkably closely to the predictions from a general model of habitat choice developed by Stamps et al. (2005). The similarity between the predictions of the 2 models with different goals and modeling techniques suggests that these finding are quite robust to the specifics of the system, the type of modeling employed, and the assumptions built into the model. Thus, our findings like those of Stamps et al. (2005) are likely to be applicable to a broad range of species facing habitat choices during dispersal. Overall, the results from this simple model taken together with the results of previous models of habitat choice suggest that a combination of the length of time available to search and the frequency and relative payoff of optimal habitat in the environment exert the greatest influence on individual settlement decisions of competent larvae. Gibson (1995) posed the question 'Why be choosy?'. We certainly do not expect this model to be the final answer to this question, but we believe that the conceptual framework we present will provide a valuable tool to researchers in the field. Likewise, we expect our study to be subject to empirical studies that prove or disprove some of our assumptions and predictions, and will therefore contribute to understanding the evolutionary factors that drive settlement specificity among marine larvae.

Acknowledgements. A summer undergraduate internship with F.S. Chia, G. Gibson and J. Pawlik first ignited this interest for R.J.T., and J. Addicott provided support and guidance that prevented him from becoming a college drop out - a sincere and heartfelt thanks to you all. We are both likewise grateful to M. Mangel, J. Rosenheim, J. Stamps, B. Tenhumberg and D. Cutler for their encouragement and assistance with various portions of this research. We also thank P. Krug, P. Marko, E. Pearson, S. Gilman, M. Frey, P. Switzer, R. Grosberg, and H. Dingle for comments and suggestions on earlier versions of this manuscript. Feedback from 3 anonymous reviewers and a particularly thoughtful and thorough review from C. Elkin and D. Marshall greatly improved this manuscript. This is contribution \#1288 from the Hawaii Institute of Marine Biology, and SOEST \#7177. RJT was supported by HIMB-NWHI Coral Reef Research Partnership (NMSP MOA 2005-008/66882). Support for this project came from NSF BioOCE\#06-23678

\section{LITERATURE CITED}

Allen JD, Zakas C, Podolsky RD (2006) Effects of egg size reduction and larval feeding on juvenile quality for a species with facultative-feeding development. J Exp Mar Biol Ecol 331:186-197

Bennett CE, Marshall DJ (2005) The relative energetic costs of the larval period, larval swimming and metamorphosis 
for the ascidian Diplosoma listerianum. Mar Freshw Behav Physiol 38:21-29

Bertness MD, Gaines SD, Bermudez D, Sanford E (1991) Extreme spatial variation in the growth and reproductive output of the acorn barnacle Semibalanus balanoides. Mar Ecol Prog Ser 75:91-100

Bishop CD, Huggett MJ, Heyland A, Hodin J, Brandhorst BP (2006) Interspecific variation in metamorphic competence in marine invertebrates: the significance for comparative investigations into the timing of metamorphosis. Integrat Comp Biol 46:662-682

Botello G, Krug PJ (2006) 'Desperate larvae' revisited: age, energy and experience affect sensitivity to settlement cues in larvae of the gastropod Alderia sp. Mar Ecol Prog Ser 312:149-159

Caswell H (1981) The evolution of 'mixed' life histories in marine invertebrates and elsewhere. Am Nat 117:529-536

Chia FS, Rice ME (eds) (1978) Settlement and metamorphosis of marine invertebrate larvae. Elsevier, New York

Chia FS, Gibson G, Qian PY (1996) Poecilogony as a reproductive strategy of marine invertebrates. Oceanol Acta 19: 203-208

Chia FS, Koss R (1988) Induction of settlement and metamorphosis of the veliger larvae of the nudibranch, Onchidoris bilamellata. Int J Invert Reprod Devel 14:53-70

Christiansen FB, Fenchel TM (1979) Evolution of marine invertebrate reproductive patterns. Theor Pop Biol 16: 267-282

Clark CW, Mangel M (2000) Dynamic state variable models in ecology: methods and applications. Oxford University Press, New York

Crisp DJ (1965) Surface chemistry, a factor in the settlement of marine invertebrate larvae. Bot Gothob Acta Univ Gothob 3:51-65

Crisp DJ (1974) Factors influencing the settlement of marine invertebrate larvae. In: Grant PT, Mackie AM (eds) Chemoreception in marine organisms. Academic Press, New York, p 177-265

Dingle H (1996) Migration: the biology of life on the move. Oxford University Press, New York

Doyle RW (1975) Settlement of planktonic larvae: a theory of habitat selection in varying environments. Am Nat 109: $113-126$

Eckert GL (1995) A novel feeding strategy of the tropical sand dollar, Encope michelini (Agassiz): adaptation to food limitation and an evolutionary link between planktotrophy and lecithotrophy. J Exp Mar Biol Ecol 187:103-128

Eggleston DB (1995) Recruitment in Nassau grouper Epinephelus striatus: post-settlement abundance, microhabitat features, and ontogenetic habitat shifts. Mar Ecol Prog Ser 124:9-22

Elkin C, Marshall DJ (2007) Desperate larvae: influence of deferred costs and habitat requirements on habitat selection. Mar Ecol Prog Ser 335:143-153

Emlet RB (1986) Facultative planktotrophy in the tropical echinoid Clypeaster rosaceus and a comparison with obligate planktotrophy in Clypeaster subdepressus (Clypeasteroida: Echinoidea). J Exp Mar Biol Ecol 95: 183-202

Fusetani N (2004) Biofouling and antifouling. Nat Prod Rep 21:94-104

Gaines S, Roughgarden J (1985) Larval settlement rate-a leading determinant of structure in an ecological community of the marine intertidal zone. Proc Nat Acad Sci USA 82:3707-3711

Gibson G (1995) Why be choosy? Temporal changes in larval sensitivity to several naturally-occurring metamorphic inducers in the opisthobranch Haminaea callidegenita. J Exp Mar Biol Ecol 194:9-24

Gibson GD, Gibson AJF (2004) Heterochrony and the evolution of poecilogony: generating larval diversity. Evolution 58:2704-2717

Gosselin LA, Qian PY (1997) Juvenile mortality in benthic marine invertebrates. Mar Ecol Prog Ser 146:265-282

Gosselin LA, Qian PY (1998) Analysing energy content: a new micro-assay and an assessment of the applicability of acid dichromate assays. Hydrobiologia 390:141-151

Grant A (1983) On the evolution of brood protection in marine benthic invertebrates. Am Nat 122:549-555

Grant A (1989) Marine invertebrate life histories: is there any value in mathematical modelling? In: Ryland JS, Tyler PA (eds) Reproduction, genetics and distributions of marine organisms. 23rd European Marine Biology Symposium, Swansea, September 5-9, 1988. Olsen \& Olsen, Fredensborg, p 91-94

Gribben PE, Marshall DJ, Steinberg PD (2006) Less inhibited with age? Larval age modifies responses to natural settlement inhibitors. Biofouling 22:101-106

Hairston NG (1989) Ecological experiments: purpose, design, and execution. Cambridge University Press, Cambridge

Harrison RG (1980) Dispersal polymorphisms in insects. Ann Rev Ecol Syst 11:95-118

Highsmith RC, Emlet RB (1986) Delayed metamorphosis effect on growth and survival of juvenile sand dollars (Echinoidea: Clypeasteroida). Bull Mar Sci 39:347-361

Jackson GA, Strathmann RR (1981) Larval mortality from offshore mixing as a link between pre-competent and competent periods of development. Am Nat 118:16-26

Jaeckle WB, Manahan DT (1992) Experimental manipulations of the organic composition of seawater: implications for studies of energy budgets in marine invertebrate larvae. J Exp Mar Biol Ecol 156:273-284

Jespersen H, Olsen K (1982) Bioenergetics in veliger larvae of Mytilus edulis L. Ophelia 21:101-113

Keough MJ (1983) Patterns of recruitment of sessile invertebrates in two subtidal habitats. J Exp Mar Biol Ecol 66: 213-245

Krug PJ (2001) Bet-hedging dispersal strategy of a specialist marine herbivore: a settlement dimorphism among sibling larvae of Alderia modesta. Mar Ecol Prog Ser 213:177-192

Lambert WJ, Todd CD (1994) Evidence for a water-borne cue inducing metamorphosis in the dorid nudibranch mollusc Adalaria proxima (Gastropoda: Nudibranchia). Mar Biol 120:265-271

Levins R, MacArthur RH (1969) An hypothesis to explain the incidence of monophagy. Ecology 50:910-911

Levitan DR (1991) Influence of body size and population density on fertilization success and reproductive output in a free-spawning invertebrate. Biol Bull 181:261-268

Mangel M (1989) Evolution of host selection in parasitoids: does the state of the parasitoid matter? Am Nat 133: 688-705

Mangel M, Clark CW (1988) Dynamic modeling in behavioral ecology. Princeton University Press, Princeton. NJ

Marshall DJ, Keough MJ (2003) Variation in the dispersal potential of non-feeding invertebrate larvae: the desperate larva hypothesis and larval size. Mar Ecol Prog Ser 255:145-153

Marshall DJ, Keough MJ (2004) When the going gets rough: effect of maternal size manipulation on larval quality. Mar Ecol Prog Ser 272:301-305

Marshall DJ, Keough MJ (2005) Offspring size effects in the marine environment: a field test for a colonial invertebrate. Austral Ecol 30:275-280 
McEdward LR, Chia FS (1991) Size and energy content of eggs from echinoderms with pelagic lecithotrophic development. J Exp Mar Biol Ecol 147:95-102

McEdward LR, Coulter LK (1987) Egg volume and energetic content are not correlated among sibling offspring of starfish: implications for life-history theory. Evolution 41: 914-917

McEdward LR, Miner BG (2001) Larval and life-cycle patterns in echinoderms. Can J Zool 79:1125-1170

McEdward LR, Morgan KH (2001) Interspecific relationships between egg size and the level of parental investment per offspring in echinoderms. Biol Bull (Woods Hole) 200: 33-50

Meadows PS, Campbell JI (1972) Habitat selection by aquatic invertebrates. Adv Mar Biol 10:271-382

Menge BA (2000) Recruitment vs. postrecruitment processes as determinants of barnacle population abundance. Ecol Monogr 70:265-288

Moran AL (1999) Size and performance of juvenile marine invertebrates: potential contrasts between intertidal and subtidal benthic habitats. Am Zool 39:304-312

Moran AL, Emlet RB (2001) Offspring size and performance in variable environments: field studies on a marine snail. Ecology 82:1597-1612

Moran AL, Manahan DT (2003) Energy metabolism during larval development of green and white abalone, Haliotis fulgens and $H$. sorenseni. Biol Bull 204:270-277

Pawlik JR (1992) Induction of marine invertebrate larval settlement - evidence for chemical cues. In: Paul VJ (ed) Explorations in chemical ecology: ecological roles of marine natural products. Cornell University Press, Ithaca, NY, p 189-236

Pawlik JR, Mense DJ (1994) Larval transport, food limitation, ontogenetic plasticity, and the recruitment of sabellariid polychaetes. In: Wilson WHJ, Stricker SA, Shinn GL (eds) Reproduction and development of marine invertebrates; Symposium, Friday Harbor, Washington, USA, June 9-11, 1992. Johns Hopkins University Press, Baltimore, MD, p 275-286

Pechenik JA (1980) Growth and energy balance during the larval lives of three prosobranch gastropods. J Exp Mar Biol Ecol 44:1-28

Pechenik JA (1990) Delayed metamorphosis by larvae of benthic marine invertebrates. Does it occur? Is there a price to pay? Ophelia 32:63-94

Pechenik JA (1999) On the advantages and disadvantages of larval stages in benthic marine invertebrate life cycles. Mar Ecol Prog Ser 177:269-297

Pechenik JA, Rice ME (2001) Influence of delayed metamorphosis on postsettlement survival and growth in the sipunculan Apionsoma misakianum. Invert Biol 120:50-57

Pechenik JA, Estrella MS, Hammer K (1996) Food limitation stimulates metamorphosis of competent larvae and alters postmetamorphic growth rate in the marine prosobranch gastropod Crepidula fornicata. Mar Biol 127:267-275

Pechenik JA, Wendt DE, Jarrett JN (1998) Metamorphosis is not a new beginning. Bioscience 48:901-910.

Pennington JT, Rumrill SS, Chia FS (1986) Stage-specific predation upon embryos and larvae of the Pacific sand dollar Dendraster excentricus by 11 species of common zooplanktonic predators. Bull Mar Sci 39:234-240

Perron FE (1986) Life-history consequences of differences in developmental mode among gastropods in the genus Conus. Bull Mar Sci 39:485-497

Phillips NE (2002) Effects of nutrition-mediated larval condition on juvenile performance in a marine mussel. Ecology 83:2562-2574
Qian PY, McEdward LR, Chia FS (1990) Effects of delayed settlement on survival, growth, and reproduction in the spionid polychaete, Polydora ligni. Invert Reprod Develop 18:147-152

Raimondi PT (1988) Settlement cues and determination of the vertical limit of an intertidal barnacle. Ecology 69:400-407

Raimondi PT, Keough MJ (1990) Behavioral variability in marine larvae. Aust J Ecol 15:427-438

Richmond RH (1987) Energetics, competence, and long-distance dispersal of planula larvae of the coral Pocillopora damicornis. Mar Biol 93:527-533

Rombough PJ (1994) Energy partitioning during fish development-additive or compensatory allocation of energy to support growth. Funct Ecol 8:178-186

Rumrill SS (1990) Natural mortality of marine invertebrate larvae. Ophelia 32:163-198

Rumrill SS, Pennington JT, Chia FS (1985) Differential susceptibility of marine invertebrate larvae: laboratory predation of sand dollar, Dendraster excentricus embryos and larvae by zoeae of the red crab, Cancer productus. J Exp Mar Biol Ecol 90:193-208

Schulze SR, Rice SA, Simon JL, Karl SA (2000) Evolution of poecilogony and the biogeography of North American populations of the polychaete Streblospio. Evolution 54: $1247-1259$

Stamps JA (2006) The silver spoon effect and habitat selection by natal dispersers. Ecol Lett 9:1179-1185

Stamps JA, Krishnan VV (2005) Nonintuitive cue use in habitat selection. Ecology 86:2860-2867

Stamps JA, Krishnan VV, Reid ML (2005) Search costs and habitat selection by dispersers. Ecology 86:510-518

Steinberg PD, Nys Rd, Kjelleberg S (2002) Chemical cues for surface colonization. J Chem Ecol 28:1935-1951

Stoner DS (1994) Larvae of a colonial ascidian use a noncontact mode of substratum selection on a coral reef. Mar Biol 121:319-326

Strathmann RR (1977) Egg size, larval development, and juvenile size in benthic marine invertebrates. Am Nat 111: 373-376

Strathmann RR (1985) Feeding and non-feeding larval development and life-history evolution in marine invertebrates. Ann Rev Ecol Syst 16:339-361

Strathmann RR, Branscomb ES, Vedder K (1981) Fatal errors in set as a cost of dispersal and the influence of intertidal flora on set of barnacles. Oecologia 48:13-18

Sulkin SD (1984) Behavioral basis of depth regulation in the larvae of brachyuran crabs. Mar Ecol Prog Ser 15:181-205

Tamburri MN, Finelli CM, Wethey DS, Zimmer-Faust RK (1996) Chemical induction of larval settlement behavior in flow. Biol Bull (Woods Hole) 191:367-373

Thorson G (1964) Light as an ecological factor in the dispersal and settlement of larvae of marine bottom invertebrates. Ophelia 1:167-208

Todd CD, Havenhand JN (1988) Physiological ecology of Adalaria proxima (Alder et Hancock) and Onchidoris muricata (Muller) (Gastropoda: Nudibranchia): III. Energy budgets. J Exp Mar Biol Ecol 118:191-205

Tooke NE, Holland DL, Gabbott PA (1985) Phospholipid fattyacid composition and cold tolerance in 2 species of barnacle, Balanus balanoides (L) and Elminius modestus Darwin. 2. Isolation and phospholipid fatty-acid composition of subcellular membrane fractions. J Exp Mar Biol Ecol 87: 255-269

Toonen RJ, Pawlik JR (1994) Foundations of gregariousness. Nature 370:511-512

Toonen RJ, Pawlik JR (1996) Settlement of the tube worm Hydroides dianthus (Polychaeta: Serpulidae): cues for 
gregarious settlement. Mar Biol 126:725-733

Toonen RJ, Pawlik JR (2001a) Foundations of gregariousness: a dispersal polymorphism among the larvae of a marine invertebrate. Evolution 55:2439-2454

Toonen RJ, Pawlik JR (2001b) Settlement of the gregarious tube worm Hydroides dianthus (Polychaeta: Serpulidae). I. Gregarious and nongregarious settlement. Mar Ecol Prog Ser 224:103-114

Toonen RJ, Pawlik JR (2001c) Settlement of the gregarious tube worm Hydroides dianthus (Polychaeta: Serpulidae). II. Testing the desperate larva hypothesis. Mar Ecol Prog Ser 224:115-131

Vance RR (1973a) More on reproductive strategies in marine benthic invertebrates. Am Nat 107:353-361

Editorial responsibility: Roger Hughes (Contributing Editor), Bangor, UK
Vance RR (1973b) On reproductive strategies in marine benthic invertebrates. Am Nat 107:339-353

Victor BC (1986) Delayed metamorphosis with reduced larval growth in a coral reef fish (Thalassoma bifasciatum). Can J Fish Aquat Sci 43:1208-1213

Ward SA (1987) Optimal habitat selection in time-limited dispersers. Am Nat 129:568-579

Wethey DS (1986) Ranking of settlement cues by barnacle larvae: influence of surface contour. Bull Mar Sci 39:393-400

Woodin SA (1991) Recruitment of infauna: positive or negative cues? Am Zool 31:797-807

Zimmer-Faust RK, Tamburri MN (1994) Chemical identity and ecological implications of a waterborne larval settlement cue. Limnol Oceanogr 39:1075-1087

Submitted: August 31, 2006; Accepted: March 6, 2007

Proofs received from author(s): October 16, 2007 